Fecha de recepción: febrero 2017 Fecha de aceptación: agosto 2017 Versión final: septiembre 2018

\section{A contribuição do design social na preservação cultural das rendeiras de biliro de Morros da Mariana}

Silvia Sasaoka ${ }^{\star}$, Giselle Marques Leite ${ }^{\star 2}$, Mônica Cristina de Moura ${ }^{\star 3}$ e Luís Carlos Paschoarelli ${ }^{\star 4}$

\begin{abstract}
Resumen: En el contexto contemporáneo, los procesos de quehaceres artesanales sufren constantes cambios bajo los impactos tecnológicos, especialmente si se considera la cultura globalizada que lleva los saberes a diferentes confrontaciones y desplazamientos. En este escenario, el diseño social se presenta como una metodología significativa para el desarrollo y la innovación de los saberes y hacer tradicionales. Este artículo demuestra la aplicación del diseño social a las acciones realizadas en el marco del proyecto de preservación de la cultura y producción de la encaje de bolillos en Morros da Mariana, Piauí. Y ofrece una reflexión sobre los presupuestos éticos, de ciudadanía, sostenibilidad e innovación social a través de la relación diseño y sociedad.
\end{abstract}

Palabras clave: diseño social - artesanía - encaje de bolillos - patrimonio cultural.

[Resúmenes en inglés y portugués en la página 95]

${ }^{(*)}$ Mestranda do Programa de Pós-Graduação em Design na Faac- Universidade Estadual Paulista Júlio de Mesquita Filho no campus de Bauru. É membro do Grupo de Pesquisa Design Contemporâneo: sistemas, objetos. Graduada em licenciatura em educação artística pelo Centro Universitário Belas Artes de São Paulo.

${ }^{\left({ }^{2}\right)}$ Museóloga, com graduação em turismo, pós-graduada em Museologia pelo Instituto de Museologia da Fundação Escola de Sociologia e Política de São Paulo. Professora de Documentação em Museus e Estudo do Objeto em cursos de museologia. Trabalhos com catalogação de coleções e projetos de organização, implantação e revitalização de museus.

(*3) Pós-Doutorada pela PUC/RJ (2012), Doutora (2003) e Mestre (1994) pela PUC/SP, bacharel em Artes Visuais e licenciada em Educação Artística / Arte Educação (1983) pela Faculdade de Belas Artes de São Paulo - FEBASP. Designer e professora com atuação nas áreas de design de interiores, gráfico, moda e mídias digitais, é pesquisadora em design contemporâneo brasileiro.

$\left.{ }^{*}{ }^{4}\right)$ Livre-docente pela UNESP (2009); Pós-doutorado pela UTLisboa (2008); Doutorado pela UFSCar (2003); Mestre pela UNESP (1997) e Graduado em Desenho Industrial pela UNESP (1994). Lider do Grupo de Pesquisa 'Design Ergonômico: Projeto e Interfaces'. Pesquisador e docente lotado no Laboratório de Ergonomia e Interfaces, do Departamen- 
to de Design, nos cursos de graduação em Design e no Programa de Pós-graduação em Design da UNESP.

\section{Introdução}

Entre 2005 e 2009, o projeto Cultura e Renda: preservação e difusão da renda de bilro aplicou na sua concepção e realização o design social como metodologia. O presente artigo é o relato desse processo de design, seus acertos, dificuldades e reflexões. O projeto, financiado através do edital Petrobras Cultural 2005 (Ver Figura 1), foi elaborado pela museóloga e proponente do projeto Giselle Marques Leite e pela gestora cultural Silvia Sasaoka a pedido das rendeiras de bilro dos Morros da Mariana, localidade no município de Ilha Grande, no Piauí, com o objetivo de tornar este saber reconhecido como patrimônio comunitário. O nome Cultura e Renda refere-se ao duplo significado da palavra renda (a técnica artesanal e o resultado de atividade econômica, rendimento) e de forma análoga foi "rendado" pelos participantes em todas as etapas de realização. Este relato é baseado na experiência da autora e a metodologia adotada para esta pesquisa deu-se a partir de abordagem qualitativa com pesquisa de campo e estudos de caso. Os principais referenciais adotados neste trabalho são Papanek, Manzini, Margolin \& Margolin, Niemeyer, Queiroz, Londres, Horta e Avelar.

Os objetivos deste estudo estão relacionados ao desenvolvimento da percepção e do repertório cultural e criativo estabelecidos pela inter-relação entre artesanato, moda e design em ações de fortalecimento da memória coletiva e do patrimônio cultural.

\section{Antes de 2005, breve histórico}

Entremear fios têxteis envolve arte, engenho e tempo; é um trabalho tradicionalmente feito por mulheres e com freqüência coletivamente. A renda de bilro chegou a Portugal através das trocas com fenícios ou com os povos do norte da Europa e ao Brasil foi trazida pelos portugueses. Esta renda aqui chegou junto com os primeiros moradores em meados do século XVII e, com o passar do tempo, rendeiras sentadas com suas almofadas embaixo de árvores e na porta das casas tornaram-se parte da paisagem do lugar.

Até a década de 1990 o trabalho das rendeiras de bilro corria risco de extinção, como ocorreu a outros grupos de artesãos, pelo desinteresse das novas gerações em aprender esse fazer e seus usos. Os jovens foram perdendo interesse pelo ofício, abandonando a cidade por centros maiores em busca de outras oportunidades de trabalho. Sem a renovação da produção e os meios de ampliação do público consumidor, o ofício definhava lentamente. Este fato é reflexo da velocidade das informações anterior à internet, que ocorria somente entre grandes centros urbanos, não alcançando as comunidades de artesãos com parco acesso de comunicação. A conexão com o novo dependia da dinâmica econômica das capitais e este sempre foi um desafio para esta parte da sociedade. O que era novo chegava à vida destas rendeiras tardiamente ou de modo distorcido pela distancia no tempo 
e espaço. A renda de bilro sempre fez parte do vestuário e sua economia ficou refém dos usos e desusos da moda, muito mais do que na decoração. De acordo com Avelar (2011) a "questão do novo" é essencial para dialogar com a dinâmica da moda e, segundo ela, para que "o novo" seja assimilado na contemporaneidade é necessário identificar-se com elementos que sejam novos e tradicionais.

Morros da Mariana, local de produção tradicional de renda de bilro, situa-se no município de Ilha Grande no delta do rio Parnaíba, a $340 \mathrm{~km}$ de Teresina, capital do estado do Piauí. Como em outros pontos do país, por falta de apoio e interesse pelas rendas, a produção foi diminuindo, as rendeiras que remanesceram foram para dentro de casa e os eventuais clientes as procuravam de casa em casa. Nos anos 1990, o governo do Estado do Piauí, através do programa estadual de artesanato sob a coordenação de Jacqueline Melo, organizou encontros com as rendeiras de Morros da Mariana e promoveu oficinas de capacitação, mobilização e associativismo em parceria com o SEBRAE PI-Serviço Brasileiro de Apoio às Micro e Pequenas Empresas do Piauí, à época sob orientação da técnica Raimunda da Silva. As oficinas estimularam as rendeiras a se associarem para melhor produzir e comercializar seus produtos. Na mesma década foi construída a primeira Casa das Rendeiras com recursos do governo do estado do Piauí e constituída juridicamente a Associação das Rendeiras de Morros da Mariana.

Em 2000, convidadas a integrar um projeto com curadoria da pesquisadora de moda Suzana Avellar para A Casa - Museu do Objeto Brasileiro (na época A Casa - Museu de Artes e Artefatos Brasileiros), as rendeiras se aproximaram do mundo da moda. O projeto foi financiado pelo Ministério da Cultura através do Fundo Nacional da Cultura (FNC) com o apoio logístico do Sebrae PI para o transporte dos profissionais. O fato de pertencerem ao segundo estado mais pobre do país e de já estarem reunidas numa gestão associativa de produção, favoreceu sua participação no projeto Moda e Artesanato, um encontro do estilista Walter Rodrigues com as rendeiras de bilro de Morros da Mariana. Apresentou-se novos usos da renda substituindo-se os fios brancos de algodão por fios de cores sóbrias, em especial o preto com composição de viscose e elastano e até fio de seda. O repertório de técnicas foi ampliado pela adaptação dos desenhos crivados em papelão para cópias reprográficas, o que permitiu ampliar os padrões sobre os quais são feitas as rendas, como mostra a Figura 2.

Até então, as rendeiras trabalhavam tradicionalmente com linha branca em peças de cama e mesa e aplicações para vestuário simples, especialmente blusas e camisolas de feitio tradicional. Novos produtos foram desenvolvidos como vestidos, saias, coletes e camisetas, que participaram do evento de moda SP Fashion Week, em 2001, lançando o trabalho das piauienses para o mundo. As mulheres passaram a ter orgulho do aumento da renda familiar, do respeito conquistado junto aos maridos e a sua comunidade da preservação da sua tradição secular. No ano de 2004, uma parceria entre a empresa de serviços em design Straat Desenvolvimento e Projetos (Peroba, 2008) e a Design Academy Eindhoven, levou estudantes de design desta escola holandesa para trabalhar com as rendeiras durante dois meses com a imersão em seu dia a dia, desenvolvendo e criando juntas uma coleção de acessórios em renda como mostra a Figura 3. 


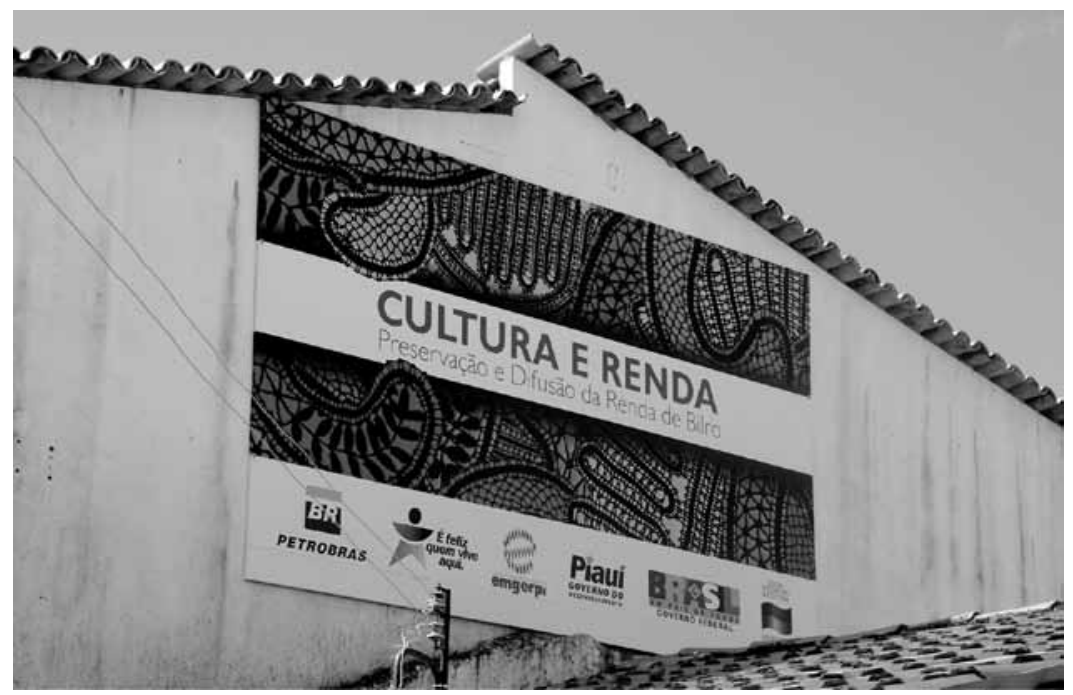

Figura 1.

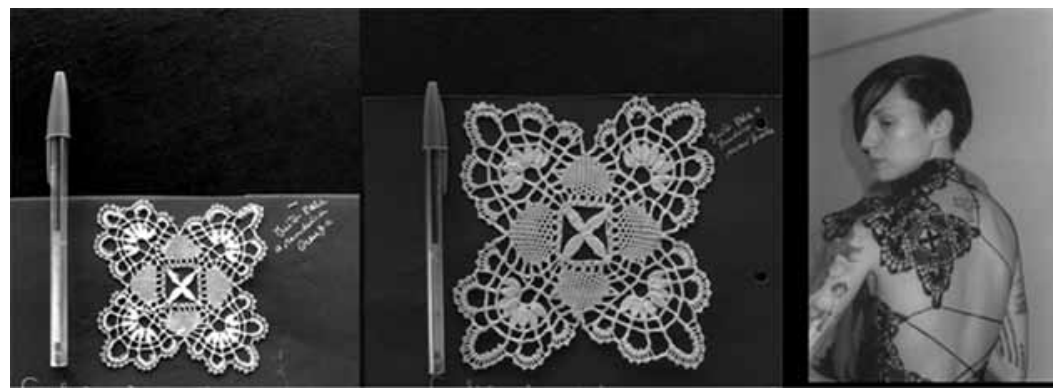

Figura 2.

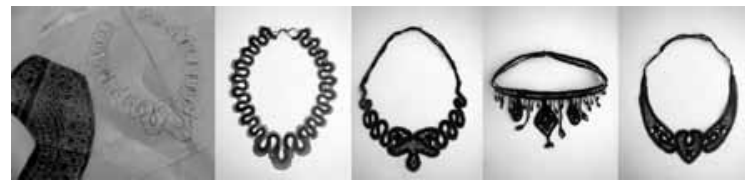

Figura 3.

Figura 1. Placa do projeto Cultura e Renda, 2009 (designer gráfico: Thomas Len Yuba). Foto: Leonardo de Paula. Figura 2. Aplicação quatro pontas em tamanho original, ampliada e elaborada em módulos na cor preta compondo vestido apresentado em passarela no SPFW Verão/2001, 2001. Foto: acervo de Associação das Rendeiras de Morros da Mariana. Figura 3. Colar criado pelas estudantes holandesas em 2004 e colares criados e produzidos pelas rendeiras em 2005. Foto: acervo de Silvia Sasaoka. 
Estes programas de geração de renda e valorização cultural fizeram o grupo crescer de oito para cento e vinte artesãs e seu trabalho repercutir pelo país, em especial no circuito da moda. Hoje a Associação das Rendeiras de Morros da Mariana é reconhecida pela qualidade de sua produção, capacidade de organização e amadurecimento dos trabalhos. O longo período de convivência da gestora cultural com as rendeiras foi imprescindível para determinar um diagnóstico preciso dos pontos chave que clamavam por transformações na Casa das Rendeiras. Durante um período de cinco anos, até a execução do Cultura e Renda em 2008, em contato frequente com as mulheres, reuniu-se uma lista de reinvindicações mescladas a sonhos particulares: a reforma da sede das rendeiras, o aprendizado de antigos pontos, a catalogação de todos os pontos de renda de bilro que já haviam realizados, entre outros.

A partir deste diagnóstico, a museóloga Giselle Marques Leite desenvolveu métodos específicos para o grupo de rendeiras. Longe de receberem o tratamento de objeto de estudo com uma perspectiva distanciada e artificial, propôs exercícios que as levassem a ocupar lugar de protagonistas das questões que concernem à sua própria história e a seu meio ambiente. A partir de conversas com as mulheres e visitas às casas de rendeiras mais experientes como Maria do Socorro Reis Galeno, presidente da associação e sua tia Dona Zezé (Maria José de Freire Galeno), uma das rendeiras mais antigas e qualificadas da cidade, a museóloga e a coordenadora do projeto visualizaram o espaço como um centro de referência de renda de bilro. Dentro de uma pequena caixa de sapatos, Dona Zezé (Ver Figura 4) guardava rendas antigas, com a idéia de um dia transmitir esse conhecimento, que ninguém mais ousava aprender pela complexidade de pontos e técnicas, e que demandavam um tempo e um espaço do qual as pessoas não dispunham mais. Era, portanto, necessário criar também um espaço de transmissão e aprendizagem para isso. Para a consolidação deste espaço de apropriação tornou-se necessária a reforma da Casa das Rendeiras A metodologia aplicada no projeto Cultura e Renda focou iluminar os valores culturais locais para possibilitar a apropriação e o reconhecimento de seus próprios saberes e que a reprodutibilidade desse conhecimento fosse aplicável para as próximas gerações de maneira sistematizada. Entende-se que o saber tradicional da renda é patrimônio comunitário que partilhado por um grupo de pessoas num determinado lugar por um período de tempo, é reconhecido como sua identidade cultural através da preservação desta cultura.

\section{Design social}

O conceito "design social" foi indicado e explorado pelo designer e professor Victor Papanek (1972). Neste livro, Papanek exorta os designers a desenvolverem programas que respondam às necessidades sociais de países e grupos pobres, vulneráveis, idosos e minorias. O design social é transdisciplinar, envolvendo sociologia, psicologia e políticas públicas e desempenha a função de tornar esses saberes inteligíveis somando-se as competências para um único fim. Nesse contexto entende-se a transdiciplinaridade como uma abordagem que "compreende o mundo presente" e atua diante de vários níveis de Realidade. (Nicolescu, 2000). E seu desenvolvimento se dá na interação do designer com as pessoas, as instituições e os lugares a que se destina. 
O design social pauta-se por questões éticas que "podem ser estabelecidas nos seguintes espaços da atividade humana, a saber: (...) normas e códigos, ou espaço do discurso e das instituições sociais em que se afirmam os deveres e as expectativas dos atores envolvidos" (Paschoarelli, Carmo, Razza, Silva, \& Silva, 2015). Nesse sentido conclui-se que é necessário o estabelecimento de critérios para atuar com pessoas. O design social também é uma intervenção social, causa impacto na vida das pessoas e nas suas formas de viver. $\mathrm{O}$ objetivo é trabalhar com o processo de design, esclarecendo-se os pressupostos sociais a serem elaborados e desenvolvidos em forma de projeto e que fará então a conexão com as pessoas envolvidas.

Por sua vez, Manzini (2014) aborda o design como "criador de lugar", uma vez que "atua em escala local criando uma nova ecologia capaz de equilibrar a relação local - global. Isto inclui criar serviços em assentamentos informais ou marginalizados em novas metrópoles, redefinir relações entre campo e cidade, criar serviços sociais enraizados nas comunidades e vizinhanças, instalar sistemas alternativos de mobilidade local e regional". O mesmo autor afirma que todo design é "co-design", resultante de um processo de "conversações sociais" que podem gerar tensões e, podemos dizer também de coautoria. E prossegue:

(...) o processo de codesign não é um espaço em que todos concordam e falam a mesma língua. É um processo em que pessoas diferentes, com diferentes ideias e linguagens interagem e, às vezes, convergem para resultados comuns. E estes resultados, exatamente porque emergem do diálogo entre ideias diferentes, podem ser especialmente interessantes, resilientes e ricos em qualidade cultural. (Manzini, 2014)

Essa dinâmica entre diversos níveis de realidade e interação ocorre no âmbito do artesanato e do design também dentro das questões de inserção socioeconômica e cultural, formando assim, um quadro para a atuação do design social. A partir da perspectiva do diálogo, Niemeyer (2013) afirma que o design está vinculado a atitudes e valores:

O Design como processo é entendido como "ação continuada", que vai desde o projeto, em que é mera possibilidade de ser, até sua presença no mundo, utilizando matéria, energia, o fazer humano como algo que afeta a vida das pessoas, transformando a sociedade e interferindo na cultura, deixando traços com seu descarte. Na contemporaneidade, os projetos de design devem, além de cumprir os requisitos de sustentabilidade, possibilitar a universalidade de seu uso, a inclusão social, a incorporação e o desenvolvimento da inovação e, além do atendimento de requisitos ergonômicos e de usabilidade, garantir satisfação de desejos, boa experiência de uso e construção de significação. O projeto de design passa a ser desenvolvido a partir do requisito referente ao modo que o seu resultado impacta o indivíduo, a sociedade, o meio ambiente (Niemeyer, 2013). 


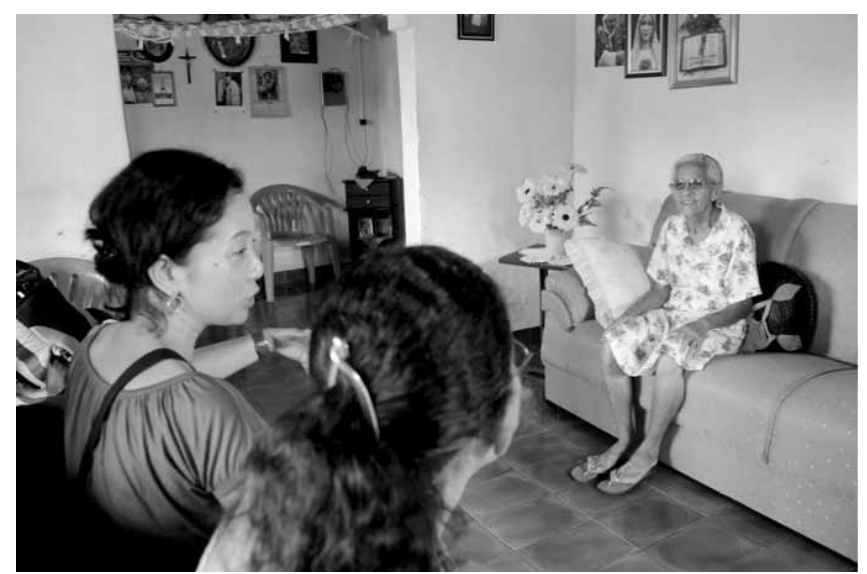

Figura 4. Conversa na casa de Dona Zezé com Socorro Reis Galeno, Giselle Marques Leite e Silvia Sasaoka, 2008. Foto: Zaida Siqueira.

Margolin e Margolin (2002) alertam para a importância da relação entre designers e o público com quem vai trabalhar a fim de promover potencialmente os aspectos positivos de ambas as partes. Os autores elaboram questões do sentido do trabalho com o design a partir da seguinte reflexão:

O design é comumente é entendido pelo público como uma prática artística que produz deslumbrante lâmpadas, móveis e automóveis. Isto é como geralmente é apresentado pela mídia e os museus. Uma das razões por que não há mais suporte para serviços de design de caráter social é a falta de pesquisa para demonstrar como um designer pode contribuir para o bem-estar humano. Uma agenda de pesquisa ampla para o projeto social deve começar por abordar uma série de perguntas. Qual o papel que um designer pode desempenhar em um processo colaborativo de intervenção social? O que atualmente está sendo feito nesse sentido e o que mais pode ser feito? Como a percepção do público de designers pode ser alterada a fim de apresentar uma imagem de um designer socialmente responsável? Como podem as agências que financiam projetos sociais e pesquisas ganhar uma percepção mais forte de design como uma atividade socialmente responsável? Quais os tipos de produtos vão de encontro às necessidades das populações vulneráveis?

Uma abordagem multifacetada pode ser tomada para explorar estas e outras perguntas. Pesquisa de levantamento e entrevistas com profissionais de serviço social, designers e administradores de agências podem ser realizadas para reunir informações sobre as percepções e atitudes e para solicitar sugestões para a mudança (Margolin \& Margolin, 2002). 


\section{Design social, aplicação}

O contato com as rendeiras de bilro de Morros da Mariana teve seu início em Moda e Artesanato, em 2001, desenvolveu-se no intercâmbio com as três estudantes de design da Holanda em 2004, e em 2005 a gestora e a museóloga elaboraram projeto para o edital Petrobras Cultural que atendesse às demandas identificadas ao longo desse processo. Cultura e Renda: preservação e difusão da renda de bilro foi tecido de forma participativa em oficinas para promover a reflexão, habilitar as rendeiras como agentes da cultura e construir uma ação comunitária. Contemplado na categoria Preservação e Memória - Patrimônio Imaterial, entre 258 aprovados de 4.742 inscritos, previa, além das ações e atividades com o grupo, a reforma da sua sede visando à ampliação de espaços para oficinas, museologia e comercialização. A Figura 5 mostra o encontro entre a museóloga, a coordenadora do projeto e as rendeiras em sua sede para expor as modificações que ocorreriam no período da reforma, concomitantemente às ações pedagógicas previstas no planejamento.

\section{Objetivos}

Os objetivos do projeto, nos aspectos culturais, sociais e econômicos, foram definidos coletivamente:

- Preservar a cultura popular por meio do apoio à produção artesanal de tradição e disseminar este conhecimento;

- Estimular o trabalho comunitário na elaboração e execução do projeto como exercício consciente da cidadania;

- Promover o trabalho das rendeiras de bilro como fonte de renda e consolidar o acesso aos mercados do artesanato, da moda, do design e do turismo.

\section{Ações}

Para atingir os objetivos do projeto, as rendeiras de Morros da Mariana participaram diretamente na definição das ações realizadas, descritas abaixo:

1. Oficinas de gestão e de transmissão de conhecimentos: as oficinas contaram com profissionais especializados contratados, as rendeiras e membros da comunidade e abrangeram: cultura e cidadania, patrimônio imaterial, arte da renda, construção conjunta da metodologia do trabalho de pesquisa, métodos de coleta, formas de registro e catalogação do material. Complementando as oficinas, apresentações e visitas a instituições ligadas ao patrimônio como o Instituto Histórico e Geográfico de Parnaíba, a Casa Inglesa e o Porto das Barcas (Parnaíba/PI).

2. Pesquisa de campo e coleta: coleta de campo das rendas, amostras, materiais, ferramentas e implementos, com registro fotográfico e em vídeo dos processos, depoimentos e entrevistas. De particular relevo uma caixa com dezenas de rendas doadas por Dona 
Zezé representante da quarta geração de uma família de rendeiras. Foram feitas entrevistas com antigas rendeiras da cidade. $\mathrm{O}$ audiovisual foi feito por profissionais para produção posterior do CD-ROM e vídeo. O registro fotográfico, com aquisição dos equipamentos necessários, foi feito pelas próprias rendeiras e membros da comunidade treinados nas oficinas, para continuidade da documentação posteriormente.

3. Oficinas de renda de bilro: ministradas pelas mestras-rendeiras, com destaque especial para as formas pouco ou não disseminadas entre as artesãs atuais, aproveitando material e técnicas registrados durante o trabalho de campo. As oficinas possibilitaram que modelos já fora de produção fossem aprendidos para disseminação. As rendas originais e as reproduzidas estão sob a guarda da Associação e as cópias poderão ser solicitadas pela comunidade para consulta e reprodução, configurando um "rendoteca".

4. Inventário de amostras de rendas e instrumentos de produção: estudo e catalogação aprofundada dos materiais coletados (amostras de rendas, materiais, riscos, padrões, implementos) realizada pelas rendeiras com orientação de profissional da área de museologia. Atividades de seleção, criação da coleção, catalogação, organização e conservação. Partiu-se da elaboração de uma ficha catalográfica básica e registro dos materiais coletados. Para realizar registro e consulta e visando a continuidade dos processos, foram adquiridos equipamentos como microcomputador, impressora com scanner e fax, além de armários e materiais de armazenamento das amostras coletadas e tratadas (embalagens, tecidos, ferramentas).

5. Intercâmbio com viagens a outros centros produtores Aracati (CE) e Florianópolis (SC): viagens de intercâmbio das rendeiras aos tradicionais centros produtores de renda de bilro no Brasil: Fortaleza/Ceará e Florianópolis/Santa Catarina, para coleta de materiais, ampliação e multiplicação dos conhecimentos. Registro para produção posterior do CD-ROM e vídeo. O intercâmbio com outros grupos de rendeiras, produziu a troca de saberes, de experiências, a ampliação da visão e o estímulo mutuo, além da difusão dos princípios do projeto. Participaram um grupo de rendeiras, a coordenação técnica do projeto, uma museóloga e a equipe de registro audiovisual. Nas cidades visitadas, participaram dos encontros com as piauienses, grupos de rendeiras de várias localidades. Foram feitas visitas a museus que tem em seus acervos coleções de rendas de bilro tais como o Museu Casa José de Alencar em Fortaleza e Museu Universitário da UFSC em Florianópolis. Nestas instituições as rendeiras puderam entrar em contato com a musealização do patrimônio, com métodos de preservação de rendas e com o trabalho profissional dos museus. Foram ainda visitados centros de comercialização de rendas, além de ter estabelecido o diálogo com produtores e comerciantes. Houve aquisição de rendas para o acervo da Associação das Rendeiras.

6. Adequação do espaço - uma arquitetura para o "fazer": a sede da Associação, como mostram as Figuras 6 e 7, foi base necessária para a execução das ações mencionadas e para a continuidade das atividades. A reforma foi projetada pelos arquitetos Celso Pazzanese e Leonardo de Paula e o projeto ampliou o espaço, duplicando a área e qualificando o ambiente entre oficina, loja e exposição. Contemplou áreas para trabalho, área específica para exposição de rendas, área de comercialização e convivência, copa, banheiros, escritório, armazenamento de acervo e trabalho museológico. Concebida também em diálogo constante com o grupo de rendeiras, foi executada com mão de obra e materiais locais, 


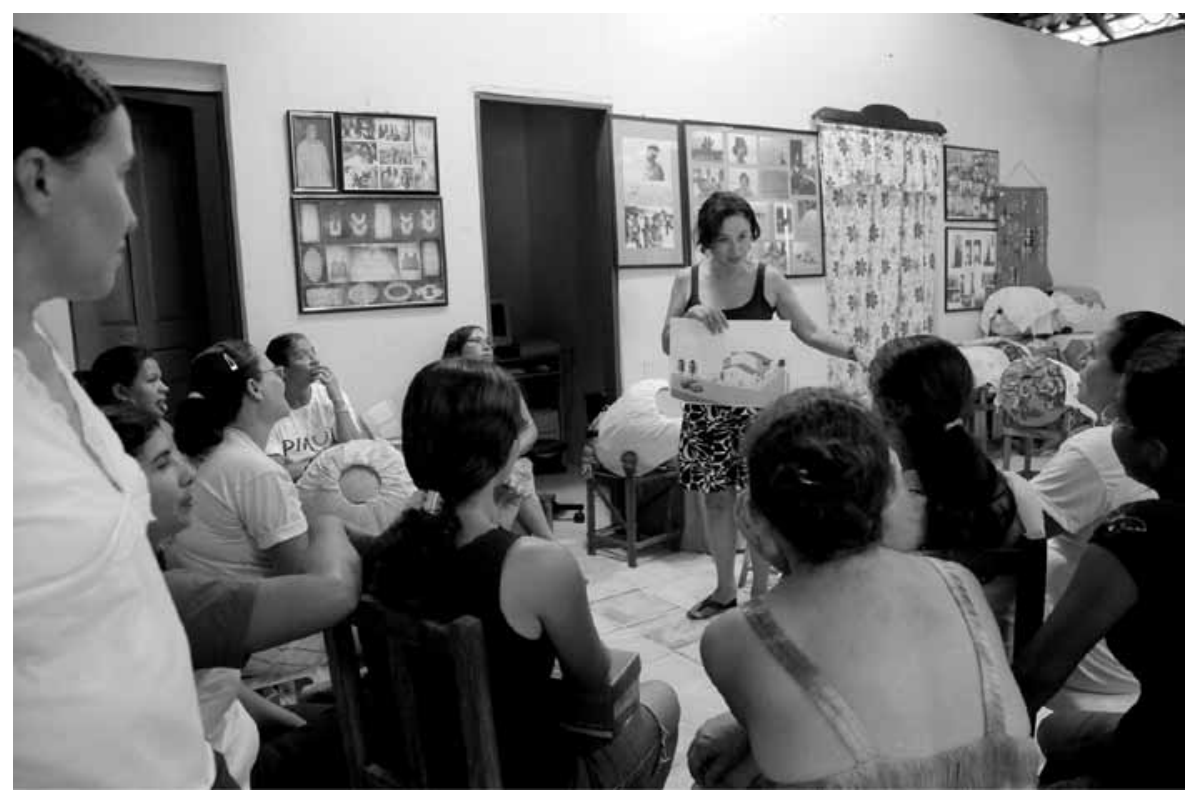

Figura 5.

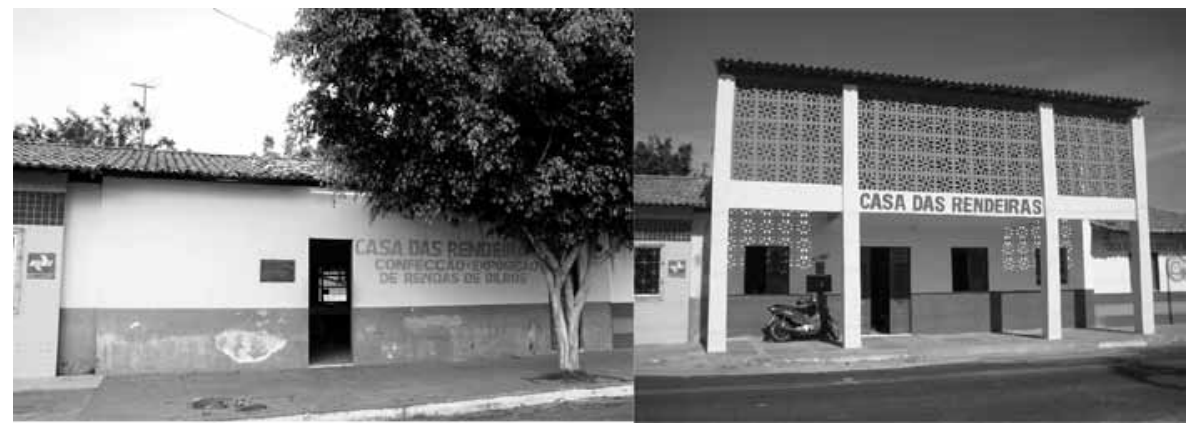

Figura 6.

Figura 5. Encontro entre rendeiras e equipe técnica para o planejamento do projeto, 2008. Foto: Zaida Siqueira. Figura 6. Sede da casa das rendeiras antes da reforma, 2008. Figura 7. Sede da casa das rendeiras após a reforma, 2008. Fotos: Zaida Siqueira (Fig. 6) e Thomas Len Yuba (Fig. 7). 
fruto de intensa convivência com o grupo, os usos, o lugar e suas referências, preservando certas características específicas dos espaços originais e inserindo os novos ambientes em diálogo e ampliando usos anteriores. A opção por mão de obra, materiais e técnicas locais -como um correspondente da proposta na área do investimento financeiro para a economia local- levou a uma simplificação técnico-construtiva correspondente às capacidades e possibilidades das mesmas, onde se adotou uma estratégia de projeto que encontrasse denominadores mínimos entre tradição e modernidade. Como exemplo dessa estratégia foi inserido um elemento arquitetônico extra ao programa base de funções, com a criação de varandas, acatando solicitação das rendeiras: estas varandas, ao serem localizadas na parte superior das duas frentes da nova construção -e terem sido dotadas de cobogós de concreto, tanto como criação de certa intimidade do fazer quanto como adequação microclimática- foram logo usadas intensamente e tornaram-se um caracterizador arquitetônico do diálogo entre tradição e conhecimento, representando a nova relevância da Associação tanto na comunidade quanto na região e criando um elemento de identificação simbólica urbanística do novo programa de funções do edifício na vila.

7. Registro audiovisual: organização e tratamento dos registros realizados (fotografias, vídeos, depoimentos) para produção de CD-ROM e vídeo de divulgação. Os registros foram copiados para a Associação das Rendeiras para memória do projeto e organizados em banco de dados para posterior acesso e pesquisa.

8. Difusão através da produção de um CD-ROM para distribuição: produção de CDROM e vídeo para divulgação do projeto, com utilização dos registros realizados durante as oficinas, trabalhos de campo e viagens de intercâmbio. Distribuição do CD-ROM à bibliotecas, universidades, centros de produção artesanal e instituições culturais. Com tiragem de 1000 exemplares foi distribuído conforme mailing apresentado ao patrocinador. Uma parte da tiragem ficou para a Associação das Rendeiras.

\section{Patrimônio cultural e design social: uma interação}

O projeto Cultura e Renda trouxe como um de seus principais fundamentos a interlocução entre a preservação de bens imateriais da cultura e o design social, acreditando na construção individual e coletiva das identidades, no exercício da cidadania através das práticas culturais próprias da comunidade, e na capacidade de autodeterminação das pessoas e grupos.

Levou em conta que os saberes ligados à confecção da renda de bilro estão conectados numa rede mais ampla de significados, envolvendo relações sociais, aspectos simbólicos, transmissão de técnicas e conhecimentos, manutenção e/ou ação criativa sobre motivos, padrões e formatos, compondo todo um tecido cultural manifesto há gerações e atualizado através do design.

Para que as proposições do design social pudessem apoiar-se sobre o universo de uma tradição artesanal já reconhecida e, mutuamente, a tradição da renda pudesse fortalecerse por intermédio de uma ação do design, o diálogo entre as vertentes envolvidas foi essencial, coordenando expectativas, desejos e fundamentações. Às necessidades expressas pelas artesãs da Associação de Rendeiras, reuniram-se, portanto, o aporte do design social 
e o viés museológico, sempre tomando o grupo de rendeiras como seu principal objeto enquanto portadoras de um saber tradicional com potencial de expansão e com grande interesse enquanto patrimônio da cultura local, regional e nacional.

O trabalho patrimonial desenvolvido com as artesãs visou, sobretudo, o reconhecimento de sua identidade e sua particularidade cultural, herdeira de uma tradição que as transcende, conectando-as a um tempo que as antecede e a um futuro que as sucede, fortalecendo o sentimento de pertencimento e continuidade. Coletar antigas amostras de renda, aprender a reproduzi-las, ensinar e tecer amostras para a coleção de empréstimos (rendoteca), recuperar instrumentos, identificar pontos e motivos decorativos, catalogar as peças, visitar pontos históricos da cidade em busca de rendas antigas, constatar em outros cenários a valorização de seu trabalho, trocar experiências e comparar produtos, falar de desejos e expectativas, constatar avanços, foram algumas das estratégias adotadas para contribuir para essa conexão, significativa para a construção e fortalecimento da autoestima, qualificação da produção e geração de renda. (Ver Figura 8)

A adequação do espaço de trabalho das rendeiras constituiu aspecto igualmente relevante para o alcance dos objetivos do projeto; além de ateliê, a edificação serviria também para local de vendas dos produtos e para oficinas de renda, considerando a oralidade e o contato direto como forma tradicional de transmissão deste saber. Objetivando ampliar a atenção sobre o fazer das rendeiras -e consequentemente de sua produção- preparou-se também um pequeno espaço expositivo, além de um local para acesso ao banco de dados sobre rendas, disponível para pesquisa. A antiga sede foi assim ampliada e qualificada, incorporando à arquitetura menções ao fazer da renda (cobogós, vazados) e elementos construtivos vernaculares da região (varandas, janelas, portas), para reforço e respeito às tradições locais. Espaço de produção no coletivo, de resignificação de saberes, de compartilhamento e fortalecimento de relações, a sede da Associação, situada à entrada de Morros da Mariana, é local de destaque e referência, ampliando o potencial simbólico do grupo de rendeiras. (Ver Figura 9)

Por sua vez, a musealização de exemplares de rendas formando uma coleção inicial, os trabalhos de salvaguarda (conservação, armazenamento, documentação), o espaço expositivo, a pesquisa realizada, constituem passo inicial para a constituição de um pequeno museu; é uma forma de devolver esse saber à população local e facilitar o acesso às manifestações da cultura, em qualquer tempo, para turistas, estudantes, pesquisadores e outros interessados. Como perspectiva futura, está a ampliação do universo patrimonial, com registro do fazer rendeiro de todo o Brasil, possibilitando intercâmbio, compreensão e o fortalecimento de tais expressões populares da cultura através de um banco de dados via site, por exemplo.

Na sua aplicação, Cultura e Renda utilizou também conceitos da educação patrimonial, tendo por princípio a construção e apropriação coletiva do conhecimento sobre o próprio patrimônio; possibilitou ao grupo interagente a compreensão da dimensão imaterial e das dinâmicas da cultura, ressignificando os fazeres e revigorando a produção. A valorização dos mestres, a transmissão do saber, o registro e comunicação desse patrimônio, configuraram o projeto como plano de salvaguarda de bens imateriais. 


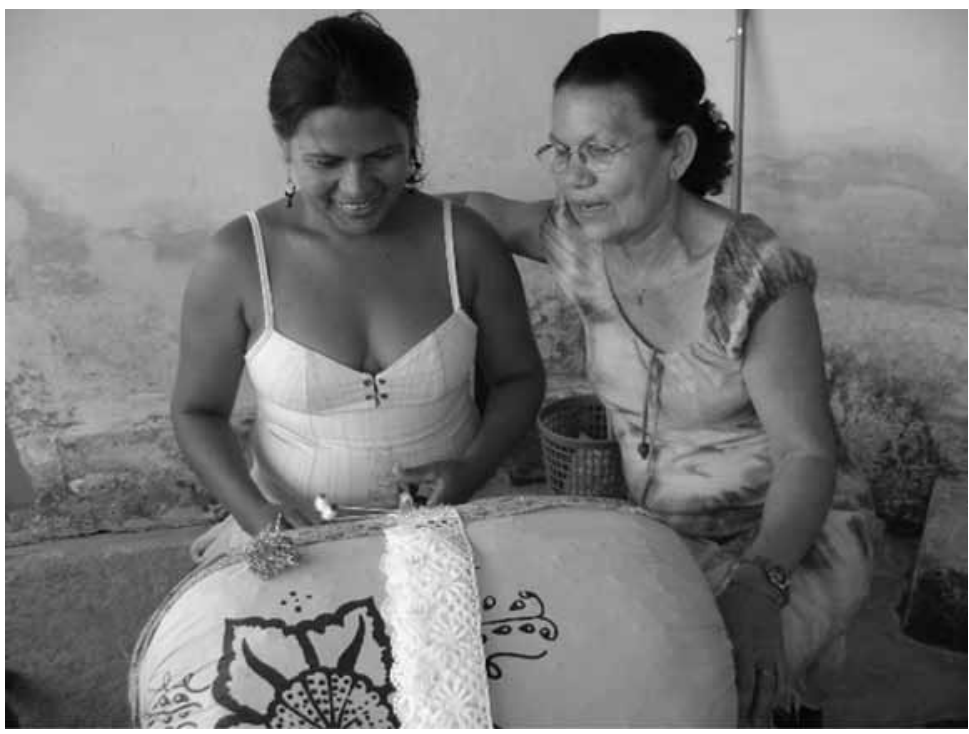

Figura 8.

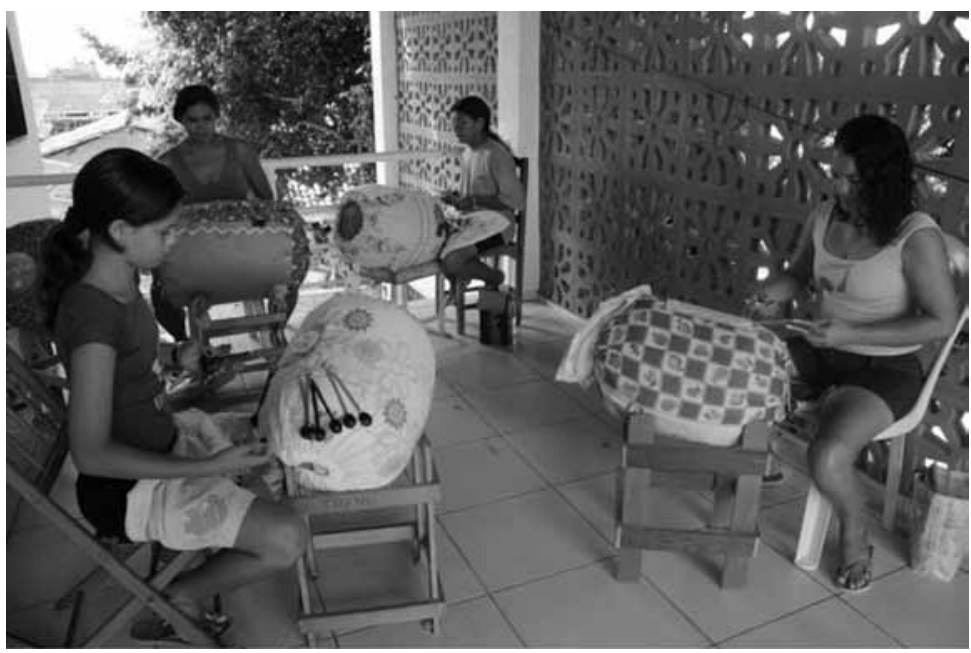

Figura 9.

Figura 8. Oficina de renda de bilro. Mestra Maria do Socorro Galeno (à direita), 2008. Foto: Zaida Siqueira. Figura 9. Grupo de artesãs na Casa das Rendeiras, 2008. Foto: Zaida Siqueira. 


\section{Considerações finais}

Este projeto identifica-se com os pressupostos do design social na metodologia aplicada e na sua proposta de ação, responsabilidade social e a ética. Aqui vale ressaltar que um projeto de tamanha abrangência não seria possível sem uma política pública que contemplasse especificamente projetos de valorização da cultura popular brasileira ligada aos saberes e fazeres. Por seu potencial de promoção da cultura local contou com o apoio, em sua fase final, do governo estadual do Piauí. Embora o projeto tivesse sido realizado através dos recursos de isenção fiscal de empresa com concessão do governo federal, as escolhas de profissionais ou decisão dos rumos do projeto foram de exclusiva competência dos proponentes e da comunidade. Dessa forma foi possível a elaboração de um projeto atendendo diretamente à demanda da comunidade. As oficinas aplicadas estimularam as rendeiras participantes a se reconhecerem e se apropriarem do seu trabalho por meio da documentação, intercâmbio e pesquisa. As informações levantadas pelas próprias rendeiras, referentes ao universo da renda de bilro, foram tecnicamente tratadas viabilizando a proteção e a difusão de seu patrimônio. O resultado até o momento permitiu que novas gerações valorizassem a renda e a comunidade possa deter e multiplicar o conhecimento, ressignificando e recuperando estes saberes. Este novo enfoque colaborou para a fixação de jovens na localidade de Morros da Mariana, aglutinados em torno tanto das novas quanto das antigas atribuições e produções do grupo. E com a organização da catalogação sistemática dos mais de mil pontos de renda, o grupo passou a receber diversos pesquisadores de design, moda e artesanato.

\section{Referências}

Avelar, S. (2011). Moda, globalização e novas tecnologias. Rio de Janeiro: Senac RJ.

Corá, M. A. J. (2013). Memória e patrimônio imaterial: formação de identidade a partir dos patrimônios culturais do Brasil. Revista NAU Social, v. 4, n. 6, p. 120-132. Retrieved from www.periodicos.adm.ufba.br/index.php/rs/article/download/312/250.

Florêncio, S. R., Clerot, P., Bezerra, J., Ramassote, R. (2012). Educação patrimonial - Histórico, conceitos e processos. Brasília: Instituto do Patrimônio Histórico e Artístico Nacional. Retrieved from http://portal.iphan.gov.br/uploads/ckfinder/arquivos/Educacao_ Patrimonial.pdf.

Horta, M. de L. P., Grunberg, E., Monteiro, A. Q. (1999). Guia básico de Educação Patrimonial. Brasília: Instituto do Patrimônio Histórico e Artístico Nacional, Museu Imperial.

Inventário nacional de referências culturais: manual de aplicação. (2000). Brasília: Instituto do Patrimônio Histórico e Artístico Nacional.

Londres, C. (2000). Referências Culturais: base para novas políticas de patrimônio. In: Manual de Publicação do Departamento de Documentação e Identificação. Brasília: MinC/Iphan.

Manzini, E. (2014). Design em um mundo conectado e em transformação. Strategic Design Research Journal, 7(2). http://doi.org/10.4013/sdrj.2014.72.06

Margolin, V., Margolin, S. (2000). A “social model” of design: issues of practice and research. Design issues, v. 18, n. 4, p. 24-30. 
Nicolescu, B. (2000). Um novo tipo de conhecimento-transdisciplinaridade. Educação e transdisciplinaridade, v. 1.

Niemeyer, L. (2013). Design e humanismo: por um novo modelo. Cadernos de Estudos Avançados em Design: Humanismo, v. 7, p. 156.

Papanek, V. (1997). Diseño para el mundo real. Tradução de Luis Cortes. Madrid: Hermann Blume Ediciones.

Paschoarelli, L. C., Carmo, C. do L., Razza, B. M., Silva, J. C. P. da, \& Silva, D. C. (2008). Questões éticas na pesquisa em design: uma abordagem sobre os relatos da produção científica. Estudos em Design, 16(1). Retrieved from http://estudosemdesign.emnuvens. com.br/design/article/view/21.

Peroba, A. R. V. (2008). Design Social: um caminho para o designer de Moda? Universidade Anhembi Morumbi, São Paulo. Retrieved from http://ppgdesign.anhembi.br/wp-content/ uploads/dissertacoes/01.pdf

Queiroz, M. N. A. (2016). Educação Patrimonial como instrumento de cidadania. Revista Museu. Retrieved from http://www.revistamuseu.com.br/artigos/art_.asp?id=3562.

\begin{abstract}
In the contemporary context, artisanal processes making face constantly undergoing changes under the technological impacts, especially if considered in a globalized culture, which takes the different confrontations and displacements. In this scenario, the social design presents itself as a significant methodology for the development and the innovation of traditional knowledge and practices. This article demonstrates the application of social design method to actions carried out within the framework of the project of preservation of culture and production of bobbin lace makers on Morros da Mariana, in Piauí State. It offers a reflection on the ethical assumptions of citizenship, sustainability and social innovation through design and society relationship.
\end{abstract}

Key words: social design - crafts - bobbin lace - cultural heritage.

Resumo: No contexto contemporâneo, os processos de fazeres artesanais sofrem constantes mudanças sob os impactos tecnológicos, especialmente se considerada uma cultura globalizada, a qual leva os saberes a diferentes confrontações e deslocamentos. Nesse cenário, o design social apresenta-se como uma metodologia significativa para o desenvolvimento e a inovação dos saberes e fazeres tradicionais. Este artigo demonstra a aplicação do design social às ações realizadas no âmbito do projeto de preservação da cultura $\mathrm{e}$ produção da renda de bilro em Morros da Mariana, Piauí. E oferece uma reflexão sobre os pressupostos éticos, de cidadania, sustentabilidade e inovação social por meio da relação design e sociedade.

Palavras chave: design social - artesanato - renda de bilro - patrimônio cultural. 